\title{
LA EFICACIA DEL TRES. DEMOCRACIA, SOCIEDAD CIVIL Y MODELO COMUNICATIVO
}

\author{
Francisco López Cantos \\ Profesor de la Universidad Jaume I de Castellón (España) \\ Email: flopez@fis.uji.es
}

\begin{abstract}
Es una experiencia eterna que todo hombre que tiene poder siente la inclinación de abusar de él, yendo hasta donde encuentra límites. Para que no pueda abusar del poder es preciso que, por la disposición de las cosas, el poder sea un control para el poder.

Montesquieu, Del espíritu de las leyes, 1748.
\end{abstract}

\section{RESUMO}

Este artigo procura discutir o conceito de Terceiro Setor Comunicativo e analisar as formas de participação da sociedade civil global nas nos sistemas democráticos. Parte do argumento de que os sistemas democráticos devem tender a poliarquia, buscando um equilíbrio entre governo, sociedade civil e mercado. Conduz sua análise levando em conta o papel do Terceiro Setor à luz do ativismo da sociedade civil e propõe uma polarização entre a cidadania ausente e o Terceiro Setor Comunicativo.

Palavras-Chave: Democracia. Terceiro Setor. Sociedade civil.

\begin{abstract}
This article is an attempt to discuss the concept of the Communicative Third Sector and to analyze the forms of global civil societal participation in democratic systems. It is based on the argument that democratic systems must tend toward poligarchy in search of a balance between government, civil society and market. The analysis takes into account the role of the Third Sector in light of civil societal activism and proposes a polarization between the absent citizenship and the Communicative Third Sector.

Key words: Democracy. Third Sector. Civil Societal
\end{abstract}

\section{Teorías de la democracia. Génesis de un deseo incumplido}

La importancia de la división de poderes para mantener la libertad y hacer gobernables los sistemas políticos había sido perfectamente comprendida desde la Grecia clásica y por autores como Locke o Maquiavelo, pero fue Montesquieu quien, como ha señalado David Held (2001, p.106), hizo de este elemento el eje central de su doctrina política. Para Montesquieu, en el contexto en que desarrolló su teoría política, la aristocracia era esencial para mantener de forma efectiva el equilibrio entre la monarquía y el pueblo, los cuales, por sí solos, tendían al despotismo, y la libertad del individuo y un 
gobierno moderado dependían de determinadas garantías contra la opresión pues consideraba que "puesto que en un estado libre todo hombre, considerado como poseedor de un alma libre, debe gobernarse por sí mismo, sería preciso que el pueblo en cuerpo desempeñara el poder legislativo" pero "como esto es imposible en los grandes estados, y como está sujeto a mil inconvenientes en los pequeños, el pueblo deberá realizar por medio de sus representantes lo que no puede hacer por sí mismo”, afirmando la necesaria complementareidad de los sistemas de gobierno representativos y la división de poderes para conformar un modelo de democracia que garantiza las libertades individuales frente al estado.

En línea con esta defensa a ultranza de la libertad y la democracia, J. Stuart Mill, ponía como condición indispensable en este modelo de democracia representativa que estuviese fundamentado en la libertad de expresión, de prensa y de reunión para proporcionar "un mecanismo mediante el cual los poderes centrales pueden ser observados y controlados" y establecer un foro (parlamento) que actúe como "perro guardián de la libertad y como centro de la razón y el debate", para así poder aprovechar "a través de la competición electoral las cualidades de liderazgo con intelecto para el máximo beneficio de todos". Cómo hace notar Held, Mill argumentaba, igualmente, que no existe alternativa deseable a la democracia representativa y que, además, había que contar con que "en sociedades grandes y complejas la participación en la vída política es, por desgracia y de manera inevitable, limitada”. Por ello, y en consecuencia, la mediación política es tan inevitable como deseable y, en definitiva, es necesario buscar sistemas de gobierno que hagan posible que esta intermediación facilite el bienestar de toda la sociedad de manera que se arbitre y controle la conformación de facciones políticas y económicas que, de otro modo, bien pudieran perpetuarse en el seno de la democracia en función de intereses particulares.

Sin embargo, en el origen mismo de este proyecto de la modernidad en la que se diseñan los sistemas políticos democráticos se comienzan a plantear muy tempranamente las contradicciones que subyacen entre la libertad y la igualdad en el programa revolucionario y las consecuencias no deseadas que se derivan del liberalismo.

En cuanto a la igualdad como limitación de las libertades individuales, tal como ha señalado Dahl (2002) releyendo La democracia en América de Tocqueville, cierto es que siendo la igualdad condición necesaria para la democracia, bien puede no serlo para la libertad, puesto que en los sistemas democráticos la decisión de la mayoría puede constituirse en una tiranía que coarte las libertades individuales. Ante este dilema, ante el que ya Tocqueville intentaba crear las condiciones necesarias para atenuar dicha contradicción, 
Dahl argumenta que para que un sistema sea plenamente democrático ha de estar basado en una participación efectiva, en la que se tenga igualdad de oportunidades para definir preferencias y ejercer el derecho a voto a partir de una comprensión bien informada de los asuntos de interés público que permita una adecuada toma de decisiones. Una solución que retoma Held (2001, p.338), bajo el paraguas ámplio del que denomina principio de autonomía y que formula de la siguiente manera:

Los individuos deberían disfrutar de los mismos derechos y, por siguiente de las mismas obligaciones) en la especificación del marco que genera y limita las oportunidades disponibles para ellos; esto es, deberían ser libres e iguales para determinar las condiciones de sus propias vidas, siempre y cuando no utilicen este marco para negar los derechos de los otros.

En este sentido, siguiendo a Held, resulta necesario concebir la democracia como un proceso de transformación que tiene como premisa el principio de que "la división entre estado y sociedad civil debe ser una característica central de la vida democrática como la idea de que el poder de adoptar decisiones debe estar libre de desigualdades y limitaciones impuestas por la apropiación privada del capital”, es decir, actualizando las preocupaciones actuales con las teorías políticas de antaño que venimos citando y subrayando así aquellas consecuencias no deseadas que ha tenido la implantación del liberalismo económico en las sociedades democráticas.

\section{Los sistemas políticos contemporaneos. Las democracias ausentes.}

En cuanto a la libertad, la acuñación del término cuarto poder se atribuye al filósofo Edmun Burke, como ha señalado Guillaumet (2003, p.35), quien, dos años antes de la Revolución Francesa, en 1787, dio cuenta de aquel momento histórico en el que el periodismo liberal se constituia como un pilar básico de la emergente modernidad y se comenzaba a conformar el modelo de sistema sociopolítico contemporáneo. En 1788 se comenzó a imprimir The Times, un año antes de que la defensa a ultranza la libertad, igualdad y fraternidad se constituyese en el eje de los sistemas democráticos contemporáneos.

Sin embargo ello ha derivado en el Global Democratic Marketplace en el que nos hallamos inmersos en la actualidad, según ha sido definido por Mattelard (1998, p.95), en el seno de complejos procesos de mundialización de la economía y la política, hunde sus raíces en la revolución industrial y en aquel liberalismo económico que ha derivado sutilmente desde la liberación de los flujos comerciales al free flow of information, basado en una Global Information Infraestructure, a la par que genera nuevos (ya viejos) discursos 
mesiánicos que recogen aquel deseo de gran familia humana con el que ya soñaban los economistas clásicos y que cada vez parecía más cerca con el avance de las tecnologías, tal como se declaraba respecto a las virtudes del telégrafo óptico de los hermanos Chappe, el primer sistema de telecomunicación, inventado en 1794: "Los pueblos modernos mediante la imprenta, la pólvora, la brújula y la lengua de los signos telegráficos han hecho desaparecer los mayores obstáculos que se oponían a la civilización de los hombres [...] permitiendo a todos los ciudadanos (de Francia) comunicar sus informaciones y voluntades".

En la modernidad, de este modo, no solo se tenía un proyecto político de en el que a los nuevos ciudadanos se les otorgaba tal estatuto a partir de la participación política con el mandato que tan bien resumía Kant respecto a la autocompresión radical que se introdujo desde la ilustración en el proceso de modernización y que invitaba a la reflexión autónoma, libre e individual: "Ten el valor de servirte de tu propio entendimiento" (SEVILLA, 2000, p.123-124), sino que se disponía, ademas, de los medios para acercar las conciencias y cumplir ese sueño igualitario que prometían los sistemas democráticos.

Sin embargo, ese proyecto de la Ilustración y de la teoría política y economica clásica ha derivado en una "sociedad sin alternativas" en la que la ausencia de la política es el único proyecto social en lo que, siguiendo los modelos sistémicos propuestos por Izusquiza (1990), Sergio Sevilla (2000, p.272-274), considera una evolución en la que "la lógica sistémica-en especial, la del sistema económico- está dotada de una potencialidad funcional tna considerable que sus efectos negativos no llegan a convertirse en contradicción interna, y su capacidad de absorción del entorno configuración de todo lo social deja poco o ningún espacio para la efectividad de políticas regulativas” dando, en definitiva, la razón a la idea de una sociedad sin hombres en la que nuestra situación social esta caracterizada por "la universalización creciente de una lógica que no tiene sujeto visible, y que sustituye los vínculos sociales por vínculos funcionales".

En ese sentido, junto a la "desertización de lo político" que provoca la incapacidad de gobernar los actuales estados con autonomía y la ausencia de un sujeto identificable, se produce un efectivo desplazamiento del centro de gravedad del poder real hacia las estructuras del mercado poniendo en profunda crisis las estructuras de gobierno diseñadas durante la modernidad sobre la base de la construcción de estados constitucionales que permitiesen hacer realidad los modelos democráticos y, en definitiva, aquellos derechos humanos que se reclamaban universales en la Revolución Francesa.

De esta manera, en la posmodernidad estamos inmersos en una "era 
del vacío”, en palabras de Lipovetsky (2002), en la que se ha producido un proceso de despersonalización, a una erosión de las formas de alteridad que "debe achacarse, al menos en parte, al proceso democrático, es decir al impulso a la igualdad", que ha derivado hacia formas nuevas de narcisismo y, también, impele a buscar nuevas formas de redefinición del ámbito de lo social con mecanismos que permitan la participación en los asuntos públicos más allá de las tradicionales instituciones civiles resultantes de la modernidad, tales como las organizaciones sindicales por ejemplo.

No obstante, y en nuestra opinión, no hemos llegado al final de la historia que pretendía Fukuyama cuando con la caída de los regímenes comunistas ya sería innecesario librar infames batallas ideológicas que no han hecho más que ralentizar la irremediable asunción de las democracias liberales como modelo socioeconómico. El fin de la historia significaría el fin de las guerras y las revoluciones sangrientas, el tiempo en que "los hombres satisfacen sus necesidades a través de la actividad económica sin tener que arriesgar sus vidas en ese tipo de batallas".

Para este popular economista, las democracias liberales para ser tales han de estar basadas necesariamente, igual que venimos relatando respecto a la teoría política de la democracia, en una economía de mercado, un gobierno representativo y en el mantenimiento de los derechos jurídicos de los ciudadanos. Sin embargo, y a partir de ello, el propio Fukuyama (2004), no se resiste al eterno intento de proponer nuevos modelos de construcción del estado y recetas de gestión para aquellos gobiernos con sus fuerzas debilitadas ante el imparable empuje de una dinámica global como la actual en que nos hallamos, pero con el ejemplar descaro que pretende que la democracia liberal y la economía de mercado es tan tan efectiva que cualquier cuestionamiento de sus principios resulta esteril. Citemosle in extenso para explicitar la ideología que subyace a un discurso como el suyo (FUKUYAMA, 2004), (las cursivas son mias):

El tipo de poder militar tradicional que asociamos con los Estados-naciones resulta cláramente insuficiente para satisfacer sus necesidades. Los europeos tienen razón en que existen formas de poder blando, como la construcción de naciones, que hay que tener en cuenta. Los países tienen que ser capaces de construir instituciones estatales no sólo dentro de sus fronteras, sino también en otros países más desorganizados y peligrosos. En otros tiempos, esto lo habrían hecho invadiendo simplemente el país y anexionándolo administrativamente a su imperio. Hoy en día, insistimos en que estamos fomentando la democracia, el autogobierno, y los derechos humanos, y en que cualquier tentativa de gobernar otros pueblos es puramente transitoria y no esconde ambición imperialista alguna. Que los europeos cuenten con unos conocimientos considerablemente superiores a los estadounidenses para resolver la cuadratura de este círculo está aún por demostrar. En todo caso, el arte de la construcción del 
Estado constituirá un elemento clave del poder nacional, tan importante como la capacidad de desplegar la fuerza militar tradicional para mantener el orden mundial.

Un discurso que, sin duda, en su desesperado intento de borrar toda la ideología sobre la que se sustenta pretende, con gran éxito entre públicos lectores, que la única alternativa real para el futuro es la intervención militar unilateral norteamerica que, quiere hacer creer, está exenta de todo interés nacional y juega una suerte de papel de policía bueno del mundo sin duda de manera más efectiva que las ideas blandas de los europeos y sus intentos vanos de fomentar la paz por otros medios.

Sin embargo, y bien a pesar del prescindible Fukuyama, el liberalismo acoge desde su propia concepción una fructífera dialéctica en su interior cuyo objetivo es, precisamente, evitar esas propuestas fundamentalistas en las que se basa el discurso de este autor y establecer mecanismos discursivos que permitan limitar los excesos de poder en el propio seno de los estados democráticos y que sirve, también, para atemperar los enfrentamientos globales en una economía mundializada como la actual.

\section{Nuevos actores en las poliarquías contemporáneas. La Sociedad Civil Global}

El análisis de Fukuyama resulta erroneo porque parte de un modelo de estado sin contradicciones internas que actua de manera coherente y conjunta sin encontrar contestación ni oposición a sus políticas, nacionales o internacionales, lo cual, sin duda, se aleja mucho de las realidades contemporáneas, que distan mucho de mostrar esos estados monolíticos que sitúan su poder por encima de todo, incluídos sus propios ciudadanos y parlamentos en los que están representados. Un país basado en una democracia liberal, como a la que se pretende adscrito Fukuyama, está fundamentado en un sistema de poderes dispersos y no unitarios en el cual, y también, las débiles formas europeas que este autor tilda de europeas de poder blando encuentren su espacio para el debate y puedean constituírse en objetivo político.

Lo que ocurre es que este flamante catedrático de la Johns Hopkins University, desconoce la potencialidad que otros de sus colegas de su misma institución vienen demostrando de un sistema político-económico global multilateral en el que participa de pleno derecho la sociedad civil y que está bien representada en la figura de Lester Salomon a quien citamos un poco más abajo.

Existe, en cualquier caso, una teoría de la democracia mucho menos excluyente y monolítica que la que subyace en el modelo económico liberal 
de Fukuyama y que explica mucho mejor la realidad contemporanea. Esta teoría se agrupa en torno a las corrientes neopluralistas, cuyo representante más visible es en la actualidad Robert Dahl (2002, p.10-20), para quien, en la tradición democrática liberal, la "democratización consta de dos dimensiones por lo menos: el debate público y el derecho a participar", en tanto que se puedan formar gobiernos democráticos caracterizados por "su continua aptitud para responder a las preferencias de sus ciudadanos", para lo cual "todos ellos deben tener igualdad de oportunidades para "formular sus preferencias; manifestar públicamente dichas preferencias entre sus partidarios, individual y colectivamente; y recibir por parte del gobierno igualdad de trato”. Para ello, y consecuencia de la aceptación de disensiones y sistemas de oposición en el seno de los sistemas democráticas, en los sistemas democráticos se debe tender a la "poliarquia", que Dahl situa como vector-objetivo deseable entre los dos ejes básicos que fundamentan las democracias: la plena liberalización del sistema para facilitar el debate público de los distintos actores y la plena representatividad para participar en las elecciones y el gobierno para, de este modo, cumplir con las promesas de igualdad y libertad para todos los ciudadanos que subyacen en los modelos democráticos. En este sentido, la democratización es sólo es una cuestión de grado y siempre un ideal difícil o imposible de lograr pero al que los sistemas sociopolíticos se pueden acercar mucho fomentando la apertura en los dos ejes descritos.

De esta manera, se ha de considerar la democracia al amparo de una teoría del conflicto, es decir, a partir de la consideración de que las dinámicas del poder y los mecanismos de toma de decisiones no derivan de sistemas monolíticos de consenso sino, bien al contrario, son el resultado de complejas negociaciones entre intereses grupales enfrentados y, en definitiva, la democracia es el resultado de la existencia de distintas facciones con objetivos diversos y distintas capacidades para poder cumplirlos.

Y, lo que es más importante de esta teoría de la "poliarquia" que desarrolla Dahl: precisamente el propio sistema político democrático está garantizado por la existencia de esas multiples grupos y la democracia ideal debe tender a ser no un gobierno de las mayorias, sino un gobierno de las minorias, en el que ningún grupo de poder puede adquirir el tamaño crítico necesario para imponerse a los demas e implantar dictaduras de facto, aún en sistemas aparentemente basados en democracias parlamentarias.

La dispersión del poder que promueven estas teorías pluralista es, en fín, el modelo sociopolítico que se está desarrollando a nivel global y que, aunque todavía embrionariamente, también está facilitando la participación a esa escala de un actor que en la tradición democrática resulta absolutamente fundamental: la sociedad civil. 
Las movilizaciones simultaneas de ciudadanos de distintos países para intentar frentar la invasión norteamericana en Irak argumentada sibilinamente por Fukuyama como vimos más arriba) ha sido la primera muestra explícita de una sociedad civil global que, igual que antaño en las naciones-estado democráticas, expresa su voz frente a un orden mundial que opera sin control político alguno a partir de los condicionantes de los mercados financieros y una economía que rebasa las fronteras nacionales.

Como ha señalado Mary Kaldor (2005, p.20-29), la acepción de la sociedad civil y su papel en el seno de la sociedad difiere entre la concepción que se tenía de la civilidad como objetivo prioritario de las personas para obtener el estatuto de ciudadanía en sociedades en que este derecho estaba restringido; aquella otra forma de entenderla netamente burguesa y que la equipara en las teorías marxistas a la aparición del capitalismo; o aquellas otras que, de un lado, ven en ella el repositorio de los nuevos activismos o, bien, intentan tamizar sus potencialidades subordinandola a los estados a partir de la delegación en ellas de responsabilidades que les son propias, tal como ocurre actualmente con el sistema de ayuda humanitaria a través de organizaciones no gubernamentales (ONG) que, sin embargo, dependen en extremos de los fondos y políticas estatales.

Todas estas acepciones de la sociedad se han venido aglutinando en torno a un nuevo agente sociopolítico y económico en el que se sintetiza la capacidad de transformación que se puede emprender desde abajo en un momento tan complejo como el actual en el que las pugnas dialéctica por el control de los discursos respecto a la sociedad civil y el papel que debe jugar en el siglo recien estrenado son, con razón, muy virulentas porque y, sin duda, es fundamental para la conformación de un sistema sociopolítico y económico que responda a las necesidades de nuestro tiempo.

\section{Las organizaciones del Tercer Sector. Activismo desde la Sociedad Civil.}

En los propios orígenes del liberalismo y en la tradición de estudios sobre nuestras sociedades industrializadas bien tempranamente se comenzaron a esbozar alternativas para resolver los crecientes problemas sociales de la modernidad. La Economía Política ya desde el siglo XIX empieza a desarrollar estudios teóricos sobre lo que se empieza a denominar Economía Social, término adoptado en el ámbito francófono, y sobre los motivos económicos que llevaron al surgimiento de las ya entonces llamadas non-profit organizations. Estas disciplinas teóricas evolucionan en el ámbito de la economía y las ciencias sociales y, hacia mediados de los años 70 , se empieza a formular lo que se ha venido conociendo desde entonces como Tercer Sector, que, tal cómo señala Herrera (1998), agruparía a todas aquellas "organizaciones autónomas no de 
beneficio que utilizan primordialmente, aunque no exclusivamente, medios simbólicos pro-sociales como la solidaridad, el don, el intercambio simbólico y mantienen una relación privilegiada de osmosis con las redes sociales primarias".

De esta manera, actualmente se adopta un planteamiento relacional entre cuatro polos, a saber: el mercado, el estado, el Tercer Sector, y las redes primarias, que están conjuntamente interactuando y en cuya dinámica el Tercer Sector habría seguido un proceso de diferenciación para cubrir precisamente aquellos ámbitos en los que el resto presentaría deficiencias. Sin embargo, esta definición asistencial del Tercer Sector sólo permite definir una parte de esta realidad puesto que este nuevo actor no es sólo producto y reacción a la quiebra del papel del estado para garantizar los sistemas de bienestar sino que es, además, la expresión de la capacidad de los ciudadanos para llevar a término el papel que les corresponde en un sistema de convivencia democrático y el protagonismo que les otorga el estatuto de ciudadanía.

Recientemente, se han delimitado las características de este Tercer Sector, que serían las siguientes, según se señala en el informe de la Johns Hopkins University:

- Organizaciones; es decir, poseen una presencia y una estructura institucionales;

- Privadas: tienen existencia institucionalmente separada del Estado;

- No reparten beneficios: no generan beneficios para sus gestores o el conjunto de titulares de las mismas;

- Autónomas: controlan esencialmente sus propias actividades;

- Con participación de voluntarios: la pertenencia a ellas no está legalmente impuesta y atraen un cierto nivel de aportaciones voluntarias de tiempo o de dinero.

Unas entidades que, como señala Lester (1999), en este informe que se ocupa de este tipo de organizaciones en múltiples países, tienen hoy una "oportunidad de incuestionable trascendencia", pues pueden "expresar las preocupaciones ciudadanas, exigir responsabilidad de los poderes públicos, promover la comunidad, cubrir necesidades insatisfechas y, en general, mejorar la calidad de vida". Es decir, un Tercer Sector situado en las fronteras de los tradicionales actores que representan el estado, el mercado y las redes primarias y que permite la apertura de espacios autónomos óptimos para impulsar acciones colectivas generadas desde la sociedad civil y, finalmente, hacer emerger esas redes sumergidas latentes propiciando la necesaria concertación de propuestas y opiniones para construir equilibrios dinámicos en las políticas económicas y las sociales.

En esta línea argumental, no es difícil entender cual es el papel 
fundamental que juega un Tercer Sector Comunicativo en nuestro maltrecho sistema democrático. No nos extenderemos sobre la importancia que tiene el que las comunidades, de cualquier ámbito, controlen el propio flujo simbólico que las convierte en tales, ni tampoco en cuestiones de identidad cultural en una dinámica global como la actual, pero sí es patente que las comunidades locales han devenido en los actores fundamentales de la mundialización para atemperar y delimitar los efectos más perversos de la liberalización económica y la mercantilización de la política y, en definitiva, el sector comunicativo local es el ámbito idóneo para desarrollar el Tercer Sector y facilitar la participación y gestión ciudadana en medios de comunicación próximos y propios.

Pero como decimos no se trata sólo, en fin, del loable deseo de dotar a la ciudadanía de los instrumentos adecuados para poder conformar una sociedad virtuosa de individuos activa que persigan grandes ideales universales, herederos de la revolución francesa y el humanismo ilustrado bajo el paraguas del celebrado redescubrimiento actual que hoy se está haciendo de lo que se viene denominando sociedad civil, sino que se trata de una necesidad más prosaica y que tiene mucho que ver con la mera supervivencia económica de nuestras sociedades y poder, a partir de una conformación sociopolítica adecuada y eficiente desde el punto de vista económico, mantener y mejorar el nivel de bienestar sociocultural de que disfrutamos en la actualidad.

Para ello, y en nuestra opinión, puede ser adecuado retomar conceptos que, aunque ya tienen un período de vida nada desdeñable, todavía pueden servir bien para entender la complejidad contemporánea, en particular, hablamos del concepto de desarrollo que, aun tratándose de un término de gran complejidad y no siendo ni siquiera un concepto universal, bien al contrario es profundamente logocéntrico y en consecuencia responde a un modelo de pensamiento básicamente, podemos convenir que remite a una suerte de mejora continua de procedimientos y conocimientos que producen cierto beneficio en nuestras sociedades al que todos aspiramos.

\section{Tercer Sector Comunicativo y modelo de desarrollo.}

El surgimiento formal del concepto de desarrollo se ha situado en torno a los años posteriores a la II Guerra Mundial a partir de la reunión de Bretton Woods en 1944 en la que se crea el Banco Internacional de Reconstrucción y Desarrollo, esto es, el Banco Mundial y, aun pudiéndose encontrar mucho más atrás, se empieza a implantar efectivamente como una opción política a partir de 1947, con la asunción por parte de Estados Unidos de los costes financieros de reconstrucción de una Europa empobrecida después de la contienda bélica, a través del conocido Plan Marshall. 
Mattelard (1993), por su parte, sitúa la implantación del concepto en el lenguaje de las relaciones internacionales un par de años después, a partir del discurso pronunciado por el presidente Truman en la Casa Blanca titulado "Punto Cuatro", con el que intenta "movilizar a la opinión pública en torno a los grandes desequilibrios sociales que amenazaban con abrirle paso al comunismo mundial", de manera que, según este autor, "la idea del progreso se metamorfoseaba en ideología del desarrollo".

Poco más adelante, UNESCO, desde 1973 en la Reunión de Argel y partiendo de la organización y estudio de las alternativas posibles para los pueblos menos favorecidos, adopta, institucionalmente y a nivel mundial, una concepción del término desarrollo que amplía su significado de manera importante para incluir en él la multiculturalidad y pluralidad de opciones para conseguir esos objetivos de mejora y, de este modo, el desarrollo se sitúa en el eje de las políticas y programas institucionales de la organización en todos los países, y se confronta este nuevo modelo global de desarrollo con la hegemónica postura paternalista que, hasta entonces, había calado profundamente en la opinión pública y venía siendo practicada habitualmente por las políticas gubernamentales de la mayoría de los países desarrollados hacia los subdesarrollados.

En Europa, en la actualidad, se ha pasado, de modo similar a cómo ocurrió con el concepto de desarrollo propuesto globalmente desde UNESCO, de una política de desarrollo regional tradicional que cómo afirma Vázquez Barbero (1999, p.47), está "basada en el modelo de crecimiento concentrado" y que proponía "favorecer la distribución territorial de la actividad productiva mediante la utilización de recursos externos al área objetivo de la ayuda", a una nueva política de desarrollo que "pretende superar los desequilibrios mediante el fomento del desarrollo de todos los territorios con potencialidades de desarrollo competitivo", sin que este crecimiento tenga por qué ser "polarizado y concentrado en las grandes ciudades".

En este nuevo enfoque, se considera que las empresas y organizaciones operan en un entorno determinado exógenamente que se ha ido formando históricamente, aunque se continúa depositando el protagonismo del crecimiento en ellas desde la clásica consideración de los productores / consumidores como agentes del mismo. Pero, no obstante, aún considerando la existencia de gran variedad de "modelos espaciales de crecimiento", se admite que "los modelos de especialización flexible cómo las redes de empresas de alta tecnología y los sistemas locales de empresas)" son las formas "más deseables de acumulación" por su mayor eficiencia económica.

En este sentido, y en el caso español, como hace notar Rodríguez Álvarez (2001, p.27), los gobiernos locales han "abierto sus campos de actuación a 
ámbitos anteriormente menos atendidos”, o no de forma prioritaria, entre los que cabe destacar el "fomento del empleo y el estímulo del desarrollo económico", empujados a asumir estas nuevas funciones.

En primer lugar, la dinámica descentralizadora comienza a extenderse a las entidades locales y, en segundo lugar, las recientes transformaciones socioeconómicas y políticas obligan a un replanteamiento del estado del bienestar que, ante las crecientes exigencias ciudadanas, obligan a que los servicios públicos se mantengan de manera eficiente tanto administrativa como económicamente. Y, en tercer lugar, la crisis del modelo clásico de crecimiento basado en las economías de escala y las grandes aglomeraciones industriales en las ciudades, obliga igualmente a un mayor protagonismo de los entes locales en el diseño de las políticas de desarrollo.

En este sentido, los orígenes de este nuevo modelo económico contemporáneo se encuentran en la crisis de las propuestas keynesianos de intervencionismo estatal que ha obligado a buscar estructuras más flexibles de gestión pública y que, en definitiva, ha acabado por conformar un modelo de desarrollo en el que se busque, sobre todo, la utilización eficiente de los recursos y la mejora continua de las sociedades con la participación conjunta de todos los agentes globales y locales.

De esta manera, el ámbito de lo local está convirtiéndose en el espacio privilegiado sobre el que se proyectan las nuevas teorías del desarrollo que, como señala este autor, se pueden emprender tanto desde la administración central o los grandes grupos industriales pero, y esto es lo más importante, también pueden iniciarse desde abajo, en una suerte de reestructuración en la que participen agentes locales públicos y privados "para obtener beneficios que redunden, en la medida de lo posible, a favor de toda la comunidad local".

Consecuencia de ello, y en el contexto actual, se hace evidente la necesidad de un continuo intercambio dialéctico entre la dinámica global y las realidades locales de manera que se puedan aprovechar los recursos externos facilitados por la economía global para obtener beneficios de explotación que repercutan localmente y faciliten estabilidad y mejoras reales en las comunidades de convivencia para lo cual, desde luego, es necesaria la participación activa de los agentes locales.

De esta manera, y tal como argumenta Vázquez Barquero (1999, p.37), el concepto contemporáneo de desarrollo se habría de entender actualmente en los términos que lo define el propio Consejo de Europa y, así, considerar genéricamente el desarrollo como aquel que "satisface las necesidades del presente sin poner en peligro la capacidad de las generaciones futuras de satisfacer sus propias necesidades". 
En definitiva, el único desarrollo posible parte de la coordinación entre actores públicos y privados, junto a la conjunción eficiente de políticas que permitan una sinergia entre las acciones arriba-abajo, que promueven el cambio estructural, y las acciones abajo-arriba, que promueven el desarrollo territorial y, sin duda, el Tercer Sector Comunicativo anclado en la sociedad civil y en el sector comunicativo local y global, es el lugar privilegiado para facilitar y fomentar estas nuevas dinámicas contemporáneas que pueden y deben progresivamente implantarse en nuestras sociedades, tanto a nivel político-económico como desde el punto de vista sociocultural.

\section{A modo de conclusión. Ciudadanías ausentes vs Tercer Sector Comu- nicativo.}

Estamos inmersos, pues, en una dialéctica específica entre esa sociedad narcisista que promueve el liberalismo económico y aquella otra en la que las formaciones sociales intermedias estan adquiriendo mayor imporancia y necesitamos que las nuevas políticas comunicativas vayan dirigidas a fomentar este nuevo modelo de sociedad civil, y es evidente que los retos son enormes y que de la conformación futura de los sistemas comunicativos, que es evidente pueden operar en una y otra dirección, va a derivar en un sistema de convivencia óptimo o, por el contrario, va a profundizar todavía más en las ya inmensas desigualdades existentes a nivel local y global, propiciando la confrontación y la violencia.

El acceso al flujo del conocimiento desde siempre ha estado en manos de las élites económicas y religiosas, y la nueva sociedad de masas emergente de la modernidad tampoco iba a ser vista en su momento con buenos ojos ante un sistema político en ciernes, la democracia, que, además de sus indiscutibles ventajas ya comentadas y de tratarse de el menos malo de los sistemas de gobierno, se generó como consecuencia de una ampliación de los mercados sustentado sobre la idea de progreso industrial.

En este nuevo contexto liberal en que surge la democracia se amplía un espacio, el de la opinión pública, que entra en contradicción con el propio sistema, diseñado para implantar un modelo de toma de decisiones políticas que corre el riesgo de someterse a la "presión de la calle", a la dictadura de las mayorías y al dictado de las leyes y, de esta manera, se hace necesario, como ha señalado Alcaraz Ramos (1994), transformar el concepto de libertad de expresión desde "su papel de instrumento de combate a otro de pacificación", y los medios de comunicación masivos se constituyen en actor fundamental para la autolegitimación del sistema.

En un estudio imprescindible para el ámbito español de mediados de los años 80 , ya se señalaba la preeminencia en la participación de las fuentes 
gubernamentales, los partidos políticos y las agencias de prensa en la elaboración de las noticias, más del 75\% del total de acontecimientos difundidos, muy por encima de las generadas por sindicatos, organizaciones sociales, y la sociedad civil en general, poniendo patente un sistema de comunicación institucionalizado y retroalimentado ad infinitum. Es decir, se ha llegado a consensuar cierta noticiabilidad de los acontecimientos asumida socialmente e instalada rutinariamente en el seno de los propios medios de comunicación, aunque no necesariamente compartida y en muchas ocasiones abiertamente criticada, como en cuanto al tratamiento informativo dado a las recientes manifestaciones ciudadanas contra la guerra de Irak.

No obstante, los movimientos sociales recientes presentan algunas diferencias notables respecto a los clásicas luchas por el reconocimiento de los derechos civiles y la ciudadanía de la era industrial, los movimientos obreros contra el capitalismo, o los más cercanos movimientos estudiantiles de los años 60. Como hace notar Meluci (1994), en estos movimientos coexisten nuevas reivindicaciones con viejas luchas y son una realidad permanente que se caracteriza por un modelo de funcionamiento "a dos polos": es habitual que nuevas propuestas surgan de una "red de pequeños grupos sumergidos en la vida cotidiana" cuando se producen problemas específicos, que son recogidas por "nucleos profesionalizados" que proporcionan "cierta unidad" y mantienen "contactos de carácter instrumental con algunas instituciones políticas”. De esta manera, estas redes sumergidas permiten que los ciudadanos se conviertan en actores políticos ocupando sólo una parte de su tiempo y pudiendo pertenecer a varios grupos, con la única condición de mantener cierta "implicación y solidaridad afectiva" entre los que pertenecen a esa red; y como contrapartida, estos sistemas de alianza permiten crear los recursos necesarios para la acción civil colectiva.

En este sentido, esta renovada capacidad de movilización de la ciudadanía, de la sociedad civil global, no está constituída en torno a modelos simplistas de interacción como los tradicionales, basados en la trasnochada "unidad de acción" y la acción civil concertada ya no puede entenderse desde el sueño comunitario, sino conociendo la heterogeneidad de la sociedad y el equilibrio dialógico en que los ciudadanos se insertan en la colectividad global desde el ámbito local, bien individualmente, bien formando esas redes sumergidas de que hablabamos, o bien formando parte de núcleos profesionalizados que operen en cualquier ámbito, y los medios de comunicación son el espacio privilegiado de interacción en esta sociedad actual, tan distinta a las anteriores.

Para entender la necesidad de sistemas de comunicación que respondan a las demandas actuales y las necesidad de un Tercer Sector Comunicativo, es 
oportuno recordar la caracterización que hacía Virilo (1995), de manera similar a Luhmann, de nuestras sociedades actuales definiéndolas como sociedades de desaparición legal, en las que se está produciendo la "eliminación completa de la visible polis de un pueblo de pleno derecho a través de la visible policía de una inquisición generalizada”, y en la que, naturalmente, el actual modelo comunicativo juega un papel relevante. En palabras de Rossi-Landi (1973), "es la muerte lingüistica o muerte comunicativa tan grave como la muerte por hambre o la civil por los trabajos forzados" y, evidentemente, una ciudadanía sin capacidad comunicativa está destinada a la desaparición.

La sociedad deseable es aquella que logra un equilibrio entre el mercado, el gobierno y la sociedad civil. Con él pensamos que es un error contraponer mercados a estado y no considerar la estrecha relación entre esta triada de agentes que se necesitan mutuamente como co-partícipes de un proyecto social compartido en el que cada uno asuma sus responsabilidades. Sin una sociedad civil estable en la que se promueva la confianza entre la ciudadanía los mercados no pueden desarrollarse y la democracia pierde legitimidad y se debilita. En palabras de Giddens (2001, p.164-167): "necesitamos reconectar estas tres esferas mediante un nuevo contrato social, apropiado para una época enla que globalización e individualismo van de la mano".

Es decir, para hacer efectivas estas terceras vías políticas necesitamos ese tercer sector comunicativo que permita a la sociedad civil interactuar con el resto de los agentes para hacer efectivo un diálogo fructífero que responda a los intereses de todos y que, en definitiva, asegure el bienestar y el desarrollo sostenible de nuestras sociedades.

Como bien ha recogido la tradición y la ciencia matemática de todos los pueblos el triángulo tiene inmensas potencialidades para explicar y atemperar lo diverso formando un nuevo constructo que, al contrario que sus elementos integrantes, posee propiedades distintivas propias que, sin que haya necesidad de mitificarlas, ofrecen nuevas perspectivas a problemas que pueden parecer irresolubles a primera vista y, en lo que nos ocupa, la introducción de un Tercer Sector Comunicativo facilita la formación de una democracia poliarquica en la que macroagentes como son la sociedad civil, el mercado y el estado puedan disponer de los instrumentos necesarios para profundizar en la libertad y la igualdad entre todos los ciudadanos y facilitar el desarrollo sostenible de nuestras sociedades. 


\section{REFERÊNCIAS}

ALCARAZ RAMOS, M. Información y poder: de prometeo a Hal 9000. Alicante: Institut de Cultura "Juan Gil-Albert”, 1994.

DAHL, Robert A. La democracia y sus crítticos. Barcelona: Paidós, 1989.

DAHL, Robert A. La democracia y sus crtticos. Barcelona: Paidós, 2002.

FUKUYAMA, F. La construcción del estado. Barcelona: Ediciones B. 2004.

GIDDENS, A. La tercera vía y sus críticos. Madrid: Taurus, 2001.

GUILLAUMET, J. Història del periodisme. Bellaterra: Universidad Autónoma de 2003.

HELD, David. Modelos de democracia, Madrid: Alianza, 2001.

HERRERA GÓMEZ, M. El Tercer Sector en los sistemas de Bienestar Social. Valencia: Tirant Lo Blanc, 1998.

IZUSQUIZA, I. La sociedad sin hombres: Niklas Luhmann o la teoría como escándalo. Barcelona: Anthropos, 1990.

KALDOR, M. La sociedad civil global: una respuesta a la guerra. Barcelona: Tusquets, 2005.

LESTER, M. Global Civil Society: dimensions of the Nonprofit Sector, Johns Hopkins Center for Civil Society Studies. Baltimore: John Hopkins

University, ${ }^{1999}$.

LIPOVETSKY G. La era del vacío. Barcelona: Anagrama, 2002.

MATTELARD, A. La comunicación-mundo. Historia de las ideas y de las estrategias. París: Fundesco, 1993.

MATTELARD, A. La mundialización de la comunicación. Barcelona: Paidós, 1998.

MELUCI, A. ¿Qué hay de nuevo en los nuevos movimientos sociales?. In: LARAÑA, E.; GUSFIELD, J. Los nuevos movimientos sociales: de la ideología a la identidad. Madrid: Centro de Investigaciones Sociológicas, 1994.

RODRÍGUEZ ÁLVAREZ, J. M. (Coord.) Experiencias prácticas de desarrollo local. 19 casos de dinamización socioeconómica en ámbitos locales. Barcelona: Bayer Hnos, Barcelona, 2001.

ROSSI-LANDI, F. Il linguaggo come lavoro e come mercato. Milán, Bompiani, cfr. Méndez Rubio, A. (1997): Encrucijadas. Elementos de crítica de la cultura. Madrid: Cátedra, 1973. SEVILLA, S. Crítica, historia y política. Madrid: Cátedra, 2000. pp. 123-124.

VÁZQUEZ, Barquero, A. La política de desarrollo local en Europa. In: GUTIÉRREZ, Fermín Rodríguez (Ed.). Manual de desarrollo local. Gijón: Trea, 1999. p. 47.

VIRILO, P. Política de la desaparición. Letra Internacional, Madrid, n. 39, p.46-48, 1995. 